\title{
Breast Reconstruction Using a TRAM Free Flap with a Mini-Abdominoplasty Design and Flap Beveling
}

Tae Hoon Kim, Kyung Won Minn, Ung Sik Jin

Department of Plastic and Reconstructive Surgery, Seoul National University Hospital, Seoul, Korea
No potential conflict of interest relevant to this article was reported.
Background One of the most common breast reconstruction techniques that uses autologous tissue is the free muscle-sparing transverse rectus abdominis myocutaneous (MS-TRAM) flap. However, patients hesitate to choose this method because of the long transverse scar between the anterior superior iliac spines. Furthermore, traditional reconstruction using a free MS-TRAM flap entails donor site morbidities such as pain, hematoma, or seroma. Here, we introduce a mini-abdominoplasty-designed free TRAM flap with flap beveling, which can be a good method for breast reconstruction in Asian patients who have small breasts.

Methods Breast reconstruction with free MS-TRAM flaps using the mini-abdominoplasty design and flap beveling was performed in 10 patients following mastectomy. Patient age, presurgical brassiere cup size, tumor type, operation type, excised breast weight, elevated flap weight, flap weight used for the breast, recipient vessel, operation time, day that the abdominal drain was removed, and complications associated with both the flap and donor site were documented for all flaps and patients.

Results For all 10 mini-abdominoplasty-designed free TRAM flap procedures, no flap loss or donor site morbidity was noted over a mean follow-up time of 16 months.

Conclusions The mini-abdominoplasty-designed free TRAM flap can safely and satisfactorily be implanted for the reconstruction of mastectomy defects. It can transfer the lower abdominal skin and subcutaneous tissue for breast reconstruction with minimal donor site scarring and morbidity, especially in Asian patients, who generally have smaller breasts.

Keywords Abdominoplasty, Mammoplasty, Myocutaneous flap

\section{INTRODUCTION}

Breast cancer is the most common malignant disease in the female population. Significant psychological, social, and sexual morbidity can follow mastectomy for treatment of breast cancer owing to the realization of the life-threatening disease as well as impaired body image [1]. Breast reconstruction improves the patient's self-confi-

Received: May 20, 2015 Revised: Jun 17, 2015 Accepted: Jun 18, 2015 Correspondence: Ung Sik Jin Department of Plastic and Reconstructive Surgery, Seoul National University Hospital, 101 Daehak-ro, Jongno-gu, Seoul 03080, Korea. E-mail: usj1011@snu.ac.kr

Copyright @ 2015 The Korean Society for Aesthetic Plastic Surgery.

This is an Open Access article distributed under the terms of the Creative Commons Attribution Non-Commercial License (http://creativecommons.org/licenses/by-nc/3.0/) which permits unrestricted non-commercial use, distribution, and reproduction in any medium, provided the original work is properly cited. www.e-aaps.org dence after the loss of a breast from cancer or trauma [2]. Of the breast reconstructions using autologous tissue, the most commonly used flaps involve a deep inferior epigastric perforator (DIEP) flap or free muscle-sparing transverse rectus abdominis myocutaneous (MS-TRAM) flap, both of which allow a sufficient volume of tissue. However, owing to the long transverse scar between the anterior superior iliac spines (ASIS), patients hesitate to choose breast reconstruction using a free MS-TRAM or DIEP flap. Furthermore, for a traditional reconstruction using a free MS-TRAM flap, the donor site must be dissected to the subcostal area in order to close the wound after elevating the flap and form the neo-umbilicus. As a result, there is an increased risk of donor site morbidity, such as pain, hematoma, or seroma. Moreover, a significant amount of the flap is discarded.

In an attempt to address these shortcomings, we developed a novel method using a mini-abdominoplasty for flap elevation, and 
we beveled the flap to contain more perforators and minimize abandoned flaps. The mini-abdominoplasty technique is intended to minimize donor site scar length and other morbidities. With regard to the donor site, recent reports focused on the abdominal sequelae associated with the strength of abdominal wall [3-5]. The aesthetic results at the donor site were rarely evaluated in most studies. We therefore sought to study the mini-abdominoplasty technique and evaluate donor site outcomes. Asian patients, who tend to have smaller breasts, can be good candidates for free flaps using a mini-abdominoplasty design to achieve sufficient volume without an evident long scar.

\section{METHODS}

\section{Study design}

This study is a retrospective review of 165 consecutive breast reconstructions performed in 161 patients with free MS-TRAM flaps, a mini-abdominoplasty design, and flap beveling following mastectomies undertaken at our institute between January 2013 and January 2014. Patient charts were reviewed for the following variables: patient age, presurgical brassiere cup size, tumor type, operation type, excised breast weight, elevated flap weight, flap weight used for the breast, recipient vessel, operation time, day that the abdominal drain was removed, and complications associated with both the flap and donor site.

\section{Surgical technique}

Patients appropriate for the mini-abdominoplasty design were selected based on preoperative physical examinations and volume assessments. Preoperative breast volume was assessed using magnetic resonance imaging [6], and preoperative abdominal volume - from the umbilicus to the symphysis pubis - was estimated using ultrasound and AutoCAD (Autodesk, Inc., San Rafael, CA, USA) [7]. The selection criteria for the mini-abdominoplasty design were as follows: abdominal volume that was twice the breast volume, mild to moderate skin laxity, excess tissue at the lower abdomen, and a sufficient distance $(>20 \mathrm{~cm}$ ) between the symphysis pubis and the umbilicus.

Preoperative markings were performed in the office 1 day prior to the operation, with the patient in the upright position. The mark for the lower abdominal incision was located on the superior aspect of the pubic hairline and laterally approached the ASIS with a gently sloped curve; however, it did not reach the ASIS. The mark for the upper abdominal incision line took into account the fact that the flap skin to be elevated usually encompasses approximately one-third to one-half of the height of the skin between the pubis and the navel. With a greater flap skin size, relocation of the umbilicus might be necessary. The key aspect of the design is to minimize the amount of skin in the flap while still providing enough skin to cover the defect. To avoid a dog-ear scar and unnecessary scar length, a lateral incision with an elliptical upper border and lazy-S shaped lower border was made. The scar is designed to be concealed by underwear. After marking the flap outline, the deep inferior epigastric artery and perforators were mapped using multidetector computed tomography (MDCT) angiography, and placement of the perforators within the designed flap was confirmed.

In the operating room, a team of general surgeons performed the mastectomy. The exact amount of the total breast skin to be excised was estimated using a sheet of paper that illustrated the skin incision performed by the general surgeons. After the mastectomy, the draping was changed, and the breast reconstruction was performed immediately. First, the flap tissue was elevated, and the incision was made as designed. Then, the subcutaneous tissue was dissected. During this procedure, a technique called 'beveled dissection' was performed to reduce the tension force applied to the abdomen; the upper portion of the abdominal subcutaneous tissue that contained a sufficient number of perforating arteries was included in the flap tissue at a greater proportion than the abdominal skin tissue. At the same time, the lower portion of the abdominal subcutaneous tissue that contained a relatively lower number of perforating arteries was left at the donor site (Fig. 1). This enables a maximum number of perforating arteries in the flap tissue with the least amount of skin tissue.

After the incision and subcutaneous bevel dissection, the flap was elevated in the same manner as a routine harvest of MS-TRAM flaps. The internal mammary artery and vein were chosen as the recipient vessels. Arteries and veins were anastomosed using interrupted $9 / 0$ or $10 / 0$ nylon sutures. The flap was tailored to the proper size and inset. The breast incisions were closed in a standard layered fashion using 3-0 and 4-0 monofilament absorbable sutures and 5-0 monofilament non-absorbable sutures. After insertion of a closed suction drain, the abdominal incision was closed in layers, with the use of interrupted 2-0 absorbable monofilament sutures to approximate the superficial fascia system, followed by interrupted 3-0 and 4-0 monofilament absorbable sutures. The skin was closed by interrupted 4-0 monofilament non-absorbable sutures. The final scar was placed above the pubis, and the umbilicus did not have to be moved.

\section{RESULTS}

\section{Patient demographics}

Of the 165 consecutive free MS-TRAM breast reconstructions performed in 161 patients, 10 breasts in 10 patients were reconstructed using the free MS-TRAM flaps with a mini-abdominoplasty design and flap beveling (mean age, 46.5 years; range, $38-58$ years) and were included in this study (Table 1), with a mean follow-up of 16 months (range, 10-24 months). The breast reconstruction was immediate in eight patients and delayed in two patients. Breast-conserving surgery was performed in one patient, total mastectomy in 




Superior

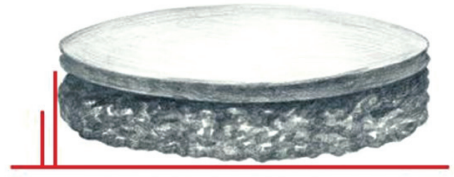

Inferior

A
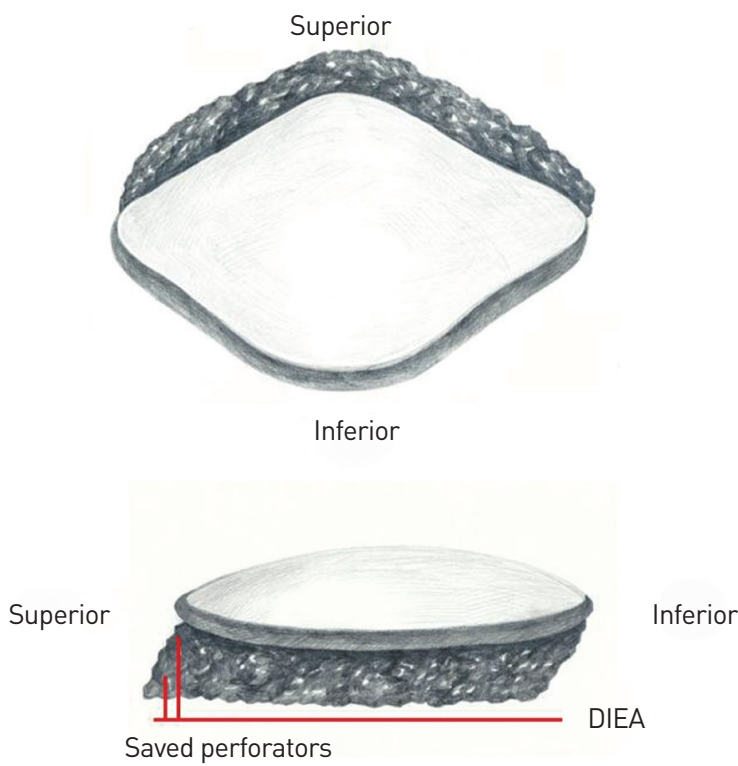

Fig. 1. Illustration of the free muscle-sparing transverse rectus abdominis myocutaneous (MS-TRAM) flap. (A) Conventional method. (B) Miniabdominoplasty-designed TRAM flap with flap beveling. Bevel dissections retain more perforators under its oblique cross-section. In contrast, conventional dissections can only obtain perforators right below the skin margin. The saved perforators are marked. DIEA, deep inferior epigastric artery.

Table 1. Characteristics of the patients who underwent breast reconstruction using free muscle-sparing transverse rectus abdominis myocutaneous flaps with a mini-abdominoplasty design and flap beveling

\begin{tabular}{|c|c|c|c|c|c|c|c|}
\hline Patient & Age (year) & BMI $\left(\mathrm{kg} / \mathrm{m}^{2}\right)$ & Bra size & Tumor type & Operation type & Reconstruction type & $\begin{array}{c}\text { Previous abdomen } \\
\text { surgery }\end{array}$ \\
\hline 1 & 46 & 22.77 & $75 B$ & IDC & BCS & Delayed & $(-)$ \\
\hline 3 & 50 & 18.71 & $75 \mathrm{~A}$ & DCIS & NSM & Immediate & $(-)$ \\
\hline 4 & 45 & 18.55 & $70 \mathrm{~A}$ & DCIS & SSM & Immediate & $(-)$ \\
\hline 5 & 38 & 19.24 & $75 \mathrm{~A}$ & IDC & NSM & Immediate & $(-)$ \\
\hline 7 & 44 & 20.2 & $75 \mathrm{~A}$ & DCIS & SSM & Delayed & $(-)$ \\
\hline 8 & 58 & 19.83 & $80 \mathrm{~A}$ & IDC & TM & Immediate & $(-)$ \\
\hline 9 & 51 & 26.71 & $85 \mathrm{~A}$ & IDC & SSM & Immediate & $(-)$ \\
\hline 10 & 38 & 17.2 & $75 \mathrm{~A}$ & IDC & SSM & Immediate & $(-)$ \\
\hline
\end{tabular}

${ }^{\text {al }}$ Cesarean section.

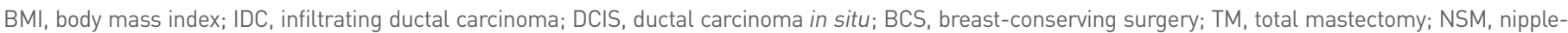
sparing mastectomy; SSM, skin-sparing mastectomy.

two patients, nipple-sparing mastectomy in three patients, and skin-sparing mastectomy in four patients. The breast sizes before mastectomies ranged from $70 \mathrm{~A}$ to $75 \mathrm{~B}$, with a cups accounting for nine (90\%) pairs of breasts and B cup for one (10\%) pair of breasts.

\section{Intraoperative details}

The intraoperative details are shown in Table 2. The mean wasted flap volume was $61.1 \mathrm{~g}$ (range, 8-126.5 g). In all groups, the recipient vessels used for the anastomoses were the internal mammary artery and vein. The mean operation time was 4.5 hours (range, 4-5.5 hours).

\section{Complications}

All free MS-TRAM flaps with a mini-abdominoplasty design and flap beveling were viable without necrosis. Wound healing was not complicated by wound dehiscence, hematoma or seroma formation, or abdominal hernia. The drain was removed when the drained volume was $<20 \mathrm{~mL}$ per day, resulting in an average duration of 4.1 
Table 2. Intraoperative details of breast reconstruction using free muscle-sparing transverse rectus abdominis myocutaneous flaps with a miniabdominoplasty design and flap beveling

\begin{tabular}{|c|c|c|c|c|c|c|}
\hline Patient & $\begin{array}{l}\text { Excised breast } \\
\text { weight (g) }\end{array}$ & $\begin{array}{l}\text { Total abdominal } \\
\text { flap (g) }\end{array}$ & $\begin{array}{c}\text { Flap weight used for } \\
\text { breast (g) }\end{array}$ & $\begin{array}{l}\text { Microsurgical } \\
\text { anastomoses }\end{array}$ & $\begin{array}{l}\text { Operation time } \\
\text { (hour) }^{\text {a) }}\end{array}$ & $\begin{array}{l}\text { Abdominal drain } \\
\text { removed (POD) }\end{array}$ \\
\hline 1 & 252 & 377 & 305 & Internal mammary & 4.5 & 3 \\
\hline 2 & 407 & 512 & 424 & Internal mammary & 4.5 & 5 \\
\hline 3 & 238.282 & 352.5 & 320 & Internal mammary & 5 & 4 \\
\hline 4 & 105 & 176 & 168 & Internal mammary & 4 & 4 \\
\hline 5 & 213 & 339.5 & 213 & Internal mammary & 4 & 5 \\
\hline 6 & 330 & 460 & 390 & Internal mammary & 5 & 4 \\
\hline 7 & 194 & 322.5 & 254.4 & Internal mammary & 4 & 4 \\
\hline 8 & 255 & 330 & 320 & Internal mammary & 4.5 & 3 \\
\hline 9 & 441 & 609 & 513 & Internal mammary & 5.5 & 4 \\
\hline 10 & 170 & 290 & 250 & Internal mammary & 4 & 5 \\
\hline
\end{tabular}

a) Total reconstruction surgery time, excluding the mastectomy. POD, postoperative date.

days (range, 3-5 days). The abdominal transverse scar was located above the level of the symphysis pubis so that it could be concealed by underwear. No scar was made at the umbilicus, and the position of the umbilicus remained stationary. Furthermore, no donor site morbidity was observed.

\section{DISCUSSION}

Breast reconstruction with TRAM flaps has shown excellent outcomes and has become the technique of choice compared with latissimus dorsi (LD), superior gluteal artery perforator (S-GAP), and superficial inferior epigastric artery (SIEA) flaps. TRAM flaps can reconstruct larger breasts than LD flaps, which are very versatile and reliable flaps that were first used for breast reconstruction in 1986 by Tazini $[8,9]$. TRAM techniques have evolved in an attempt to reduce the morbidity of the abdominal wall and improve the aesthetics of the reconstructed breast [10]. Regarding donor site morbidity, previous studies have indicated that the excised amount of the rectus muscle and anterior rectus sheath is minimized and complications such as abdominal bulging or herniation are decreased with TRAM flaps $[11,12]$. Furthermore, limited undermining can reduce complications associated with abdominal wound healing [13]. The mini-abdominoplasty design was suggested to further reduce these donor site morbidities. By elevating the smallest possible amount of flap tissue, reductions are possible in the range of dissection, resection of muscle and fascia, and amount of skin tissue to be excised. Therefore, the tension force applied on the abdomen is minimized. As a result, no donor site morbidities were observed in this study.

In this study, all flap tissue was viable without necrosis. Recent reports show that more perforators are located in the superior quadrant than in the lower quadrant [14-16]. Therefore, to maximize the viability of the flap tissue, the flap contains more of the upper portion of the abdominal subcutaneous tissue, which contains a sufficient number of perforating arteries. Meanwhile, the lower portion of the abdominal tissue is left at the donor site to minimize the tension force applied on the abdomen. This is referred to as the 'beveled' dissection technique, which enables a sufficient number of perforating arteries to be included in the flap tissue as well as the disconnection of the distal part of the perforating arteries located in the upper portion of the abdominal subcutaneous tissue. The MS-TRAM technique not only harvests at least three to four perforating arteries in each flap tissue but also directly links blood vessels that existed between the perforating arteries [17]. This results in greater chance of flap survival because the flap tissue consists of a greater number of perforating arteries with disconnected distal ends.

In addition, imaging techniques such as MDCT angiography facilitate the preoperative decision regarding which perforators are most suitable, reducing the stress and time spent by the surgeon in choosing the perforator and enabling safe ligation of the other perforators [18]. Using MDCT angiography to confirm the perforators in the designated area preoperatively, we used the internal mammary vessels as the recipient vessels, which provide freedom of movement of the flap. Because the internal mammary artery has good flow compared with the thoracodorsal artery, it can act as a reliable recipient vessel [19].

Ideal candidates for breast reconstruction with a free TRAM flap using the mini-abdominoplasty design are patients who undergo a mastectomy and are displeased with their lower abdominal contour, not obese, have excess abdominal tissue confined to the lower abdomen, and are small to medium breasted. Contraindications are large breasts and large defects. The mini-abdominoplasty design should not be used with women who are obese or have ex- 

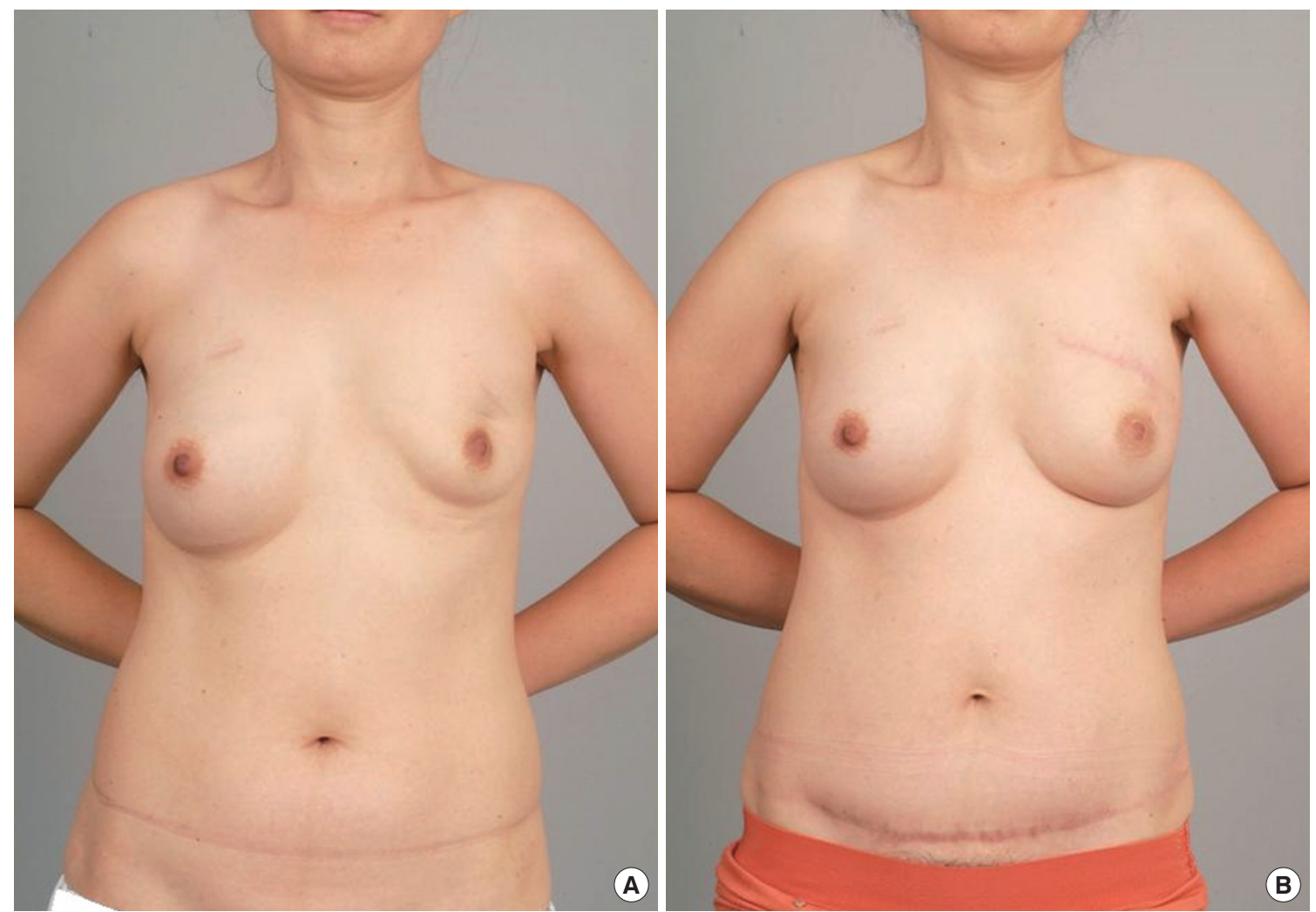

Fig. 2. Pre-/Postoperative photography (Patient 1). (A) Patient with left breast deformity due to previous breast surgery. (B) Twelve months after breast reconstruction with a mini-abdominoplasty-designed transverse rectus abdominis myocutaneous (TRAM) flap with flap beveling. The lower abdominal transverse scar can be concealed by underwear, and there is no periumbilical scar.

cessive soft tissue in the upper abdomen. Therefore, each patient needs to be carefully assessed to determine the appropriate procedure [20]. A free TRAM flap using a mini-abdominoplasty design and flap beveling is well suited for Asian women, who, in comparison to women of other races, have relatively smaller breasts and lower incidence of obesity.

We did not move the position of the umbilicus, with the aim of reducing the scar size and minimizing the extent of dissection. However, this is also problematic because the amount of harvested flap tissue limits the surgical indication to women with small breasts and smaller body mass indices. To overcome this problem, umbilical transection [21] could be performed during the elevation of the flap tissue. In this way, a scar would not develop around the umbilicus, the range of dissection would be minimized, and most importantly, a greater volume of flap tissue could be harvested.

The most significant superiority of this design is the reduced length of abdominal scars and the avoidance of periumbilical scars. No patients developed hypertrophic donor site scars or other complications. All 10 patients showed high level of satisfaction after the procedure using this design.

Cases of immediate reconstruction after the total mastectomy and cases of delayed breast reconstruction were included for this study. The included patients had small breast sizes and minimal skin requirements for the reconstruction. With no differences in the surgical procedures, all patients went through reconstructions successfully with the new design.

This study has some limitations. First, the study was retrospective in nature, and the sample size was small. A larger sample size and longer follow-up are needed to lend additional support to the conclusions. Although the present study shows that the bevel dissection technique is beneficial for the viability of the flap tissue, additional scientific evidence is needed.

Nevertheless, in light of these considerations and our practical experiences, autologous breast reconstruction with a mini-abdominoplasty-designed free TRAM flap with flap beveling transfers the lower abdominal skin and subcutaneous tissue, resulting in an aesthetically pleasing breast reconstruction with minimal donor site scarring and morbidity, especially in Asian patients, who tend to have smaller breasts (Fig. 2 and 3).

\section{PATIENT CONSENT}

Patients provided written consent for the use of their images. 

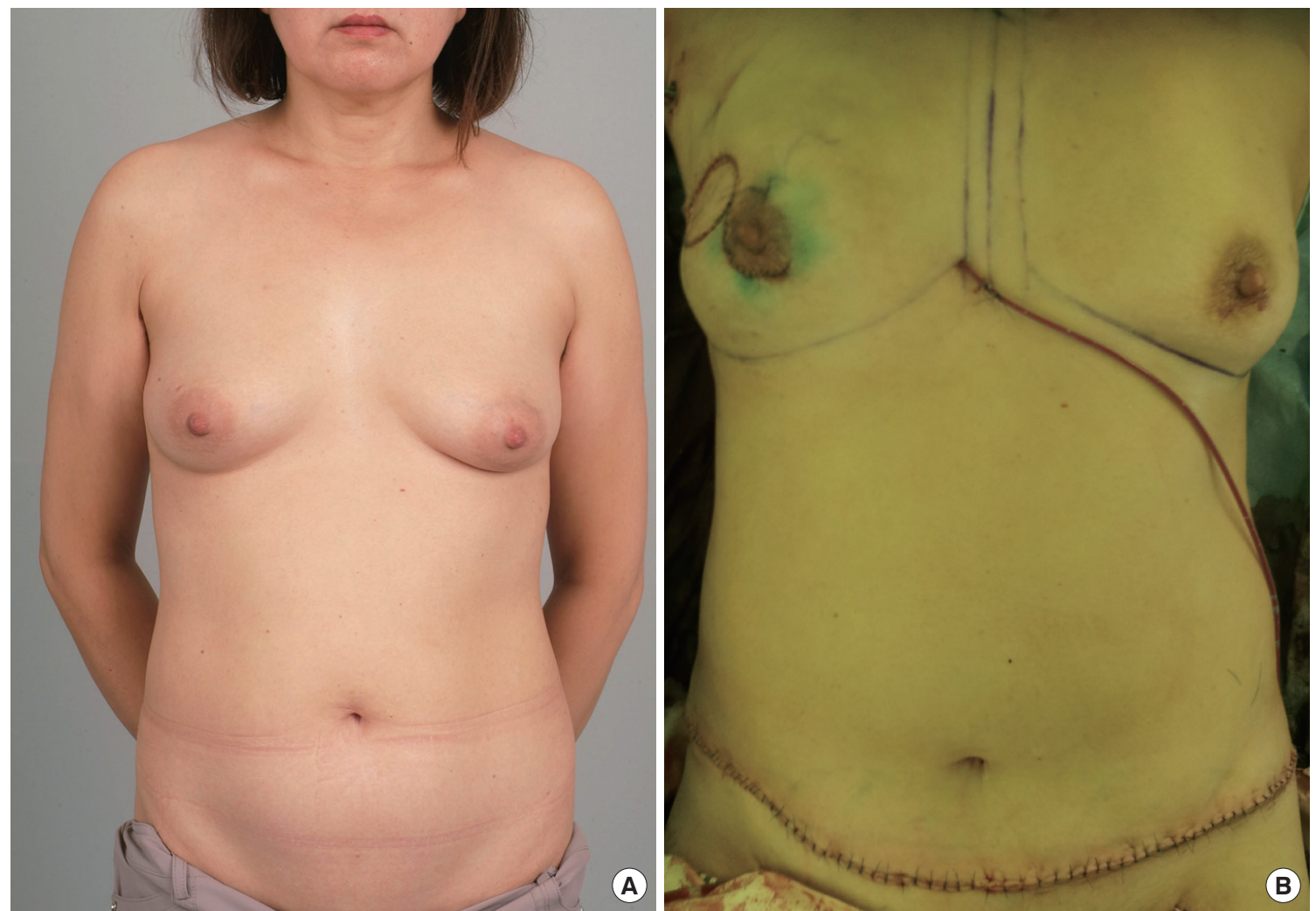

Fig. 3. Pre-/Postoperative photography (Patient 3). (A) Patient with right breast cancer. (B) Immediate postoperative photography of breast reconstruction with a mini-abdominoplasty-designed transverse rectus abdominis myocutaneous (TRAM) flap with flap beveling.

\section{REFERENCES}

1. Weitzner MA, Meyers CA, Stuebing KK, et al. Relationship between quality of life and mood in long-term survivors of breast cancer treated with mastectomy. Support Care Cancer 1997;5:241-8.

2. Schain W. Psychosocial factors in mastectomy and reconstruction. In: Noone RB, editor. Plastic and reconstructive surgery of the breast. Pennsylvania, PA: Decker; 1991. p. 327-43.

3. Momeni A, Kim RY, Heier M, et al. Abdominal wall strength: a matchedpair analysis comparing muscle-sparing TRAM flap donor-site morbidity with the effects of abdominoplasty. Plast Reconstr Surg 2010; 126:1454-9.

4. Israeli R, Hazani R, Feingold RS, et al. Extended mesh repair with external oblique muscle reinforcement for abdominal wall contour abnormalities following TRAM flap. Ann Plast Surg 2009;63:654-8.

5. Chang EI, Chang EI, Soto-Miranda MA, et al. Comprehensive analysis of donor-site morbidity in abdominally based free flap breast reconstruction. Plast Reconstr Surg 2013;132:1383-91.

6. Yoo A, Minn KW, Jin US. Magnetic resonance imaging-based volumetric analysis and its relationship to actual breast weight. Arch Plast Surg 2013;40:203-8.

7. Minn KW, Hong KY, Lee SW. Preoperative TRAM free flap volume estimation for breast reconstruction in lean patients. Ann Plast Surg
2010;64:397-401.

8. Purpura F. Tansini method for the cure of cancer of the breast. Lancet 1908; 171:634-7.

9. D'Este S. La technique de l'amputation de la mamelle pour carcinoma mammaire. Rev Chir 1912;45:164-210.

10. Nahabedian MY, Momen B, Galdino G, et al. Breast Reconstruction with the free TRAM or DIEP flap: patient selection, choice of flap, and outcome. Plast Reconstr Surg 2002;110:466-75.

11. Nahabedian MY, Dooley W, Singh N, et al. Contour abnormalities of the abdomen after breast reconstruction with abdominal flaps: the role of muscle preservation. Plast Reconstr Surg 2002;109:91-101.

12. Nahabedian MY, Manson PN. Contour abnormalities of the abdomen after transverse rectus abdominis muscle flap breast reconstruction: a multifactorial analysis. Plast Reconstr Surg 2002;109:81-7.

13. Mayr M, Holm C, Höfter E, et al. Effects of aesthetic abdominoplasty on abdominal wall perfusion: a quantitative evaluation. Plast Reconstr Surg 2004;114:1586-94.

14. Munhoz AM, Ishida LH, Sturtz GP, et al. Importance of lateral row perforator vessels in deep inferior epigastric perforator flap harvesting. Plast Reconstr Surg 2004;113:517-24.

15. Offman SL, Geddes CR, Tang M, et al. The vascular basis of perforator flaps based on the source arteries of the lateral lumbar region. Plast Reconstr Surg 2005;115:1651-9. 
16. Tansatit T, Chokrungvaranont P, Sanguansit P, et al. Neurovascular anatomy of the deep inferior epigastric perforator flap for breast reconstruction. J Med Assoc Thai 2006;89:1630-40.

17. Bailey SH, Saint-Cyr M, Wong C, et al. The single dominant medial row perforator DIEP flap in breast reconstruction: three-dimensional perforasome and clinical results. Plast Reconstr Surg 2010;126:739-51.

18. Masia J, Kosutic D, Clavero JA, et al. Preoperative computed tomographic angiogram for deep inferior epigastric artery perforator flap breast reconstruction. J Reconstr Microsurg 2010;26:21-8.
19. Blondeel PN, Arnstein M, Verstraete K, et al. Venous congestion and blood flow in free transverse rectus abdominis myocutaneous and deep inferior epigastric perforator flaps. Plast Reconstr Surg 2000;106: 1295-9.

20. Sozer SO, Agullo FJ, Santillan AA, et al. Decision making in abdominoplasty. Aesthetic Plast Surg 2007;31:117-27.

21. Colwell AS, Kpodzo D, Gallico GG 3rd. Low scar abdominoplasty with inferior positioning of the umbilicus. Ann Plast Surg 2010;64: $639-44$. 